\title{
DECOMPOSITION OF MANUFACTURING PROCESSES: A REVIEW
}

\author{
N.M.Z.N. Mohamed ${ }^{1,2}$ and M. K. Khan ${ }^{1}$ \\ School of Engineering, Design and Technology, \\ University of Bradford, Bradford, UK \\ E-mail:nikzuki@ump.edu.my; m.k.khan@bradford.ac.uk \\ ${ }^{2}$ Faculty of Mechanical Engineering, Universiti Malaysia Pahang, \\ Pahang Darul Makmur, Malaysia
}

\begin{abstract}
Manufacturing is a global activity that started during the industrial revolution in the late 19 th century to cater for the large-scale production of products. Since then, manufacturing has changed tremendously through the innovations of technology, processes, materials, communication and transportation. The major challenge facing manufacturing is to produce more products using less material, less energy and less involvement of labour. To face these challenges, manufacturing companies must have a strategy and competitive priority in order for them to compete in a dynamic market. A review of the literature on the decomposition of manufacturing processes outlines three main processes, namely: high volume, medium volume and low volume. The decomposition shows that each sub process has its own characteristics and depends on the nature of the firm's business. Two extreme processes are continuous line production (fast extreme) and project shop (slow extreme). Other processes are in between these two extremes of the manufacturing spectrum. Process flow patterns become less complex with cellular, line and continuous flow compared with jobbing and project. The review also indicates that when the product is high variety and low volume, project or functional production is applied.
\end{abstract}

Keywords: manufacturing processes, high volume, medium volume, low volume

\section{INTRODUCTION}

According to Miltenburg (2008), the competitive strength of a manufacturing company is based on its structural and infrastructural readiness. Capacity, facilities, technology and sourcing comprise four structural areas. The infrastructural areas are the workforce, quality, production planning, and organisation. According to Swink et al. (2007), a company must have a specific and strategic goal, based on individual competitive strength, in order to compete in the marketplace. Furthermore, according to Balakrishnan et al. (2007), the global competitiveness of economic manufacturing is striving for high quality products and low prices. This is due to dynamic competition among the manufacturers in securing their customers (Kost and Zdanowicz, 2005). The demand for high quality, low cost and on-time delivery has resulted in market fluctuations and greatly increased product choice.

Quality conformance processes help to reduce costs, raise productivity and promote reputation in the global market place. According to Amoako-Gyampah and Acquaah (2008), a quality strategy plays an important role in capturing customer 
satisfaction that can potentially lead to sales growth and increased market share. They also added that a company that develops a strategy to achieve volume and mixed flexibility, whilst maintaining low costs and high quality, will be able to react faster to market demands and achieve higher performance. A recent study by Karim et al. (2008), revealed that product quality and reliability (Q\&R) has become the main global competitive factor. According to Stewart (2010), sometimes too much growth in demand can take focus away from quality, which results in defective products reaching the market, such as in the case of the Toyota Motor Corporation, which resulted in tremendous costs (financial and reputation) for the company.

\section{RESEARCH BACKGROUND}

The word manufacture is believed to be derived from two Latin words, manus (hand) and factus (make) and thus means make by hand (Váncza and Egri, 2006). In the era of global competition, the level of manufacturing capability will determine the economic status of a particular country (Castaldi, 2009). According to Groover (2007), manufacturing is the application of physical and chemical processes to a material by altering the material's geometry, properties and appearance, in order to make parts or products. Manufacturing also involves the application of tools, machines, power and manual labour to the transformation of raw materials into finished products (Wang et al., 2009). Furthermore, in many manufacturing activities, multiple component parts are assembled to make final products (Boysen et al., 2009). The manufacturing operation is almost always carried out in sequential processes from one operation to another, with each process bringing the material closer to the end product. There are two basic types of manufacturing process: processing operations and assembly operations (Groover, 2007). Processing operations transform a material from one level of completion to a more advanced level that is closer to the final designed product. The processes continue until the final product is completed. For instance, when sand is processed into glass, iron ore is transformed into steel, or when petroleum is refined into plastics. Through the process the product becomes even more valuable, for example, when the plastic is moulded into complex shapes. These processes add value to the starting material by changing its geometry, properties, or appearance. On the other hand, an assembly operation joins two or more parts or components to become a new entity, which is known as an assembly or subassembly (Panchalavarapu et al., 2005). Some of the joining methods are welding, brazing and fastening (Kalpakjian and Schmid, 2006). The important point is that both processes and assembly operations add value to the original material by altering its shape or properties. Every manufacturer is aiming to reduce the processes to the minimum operation without affecting the desired product in order to become competitive.

\section{DECOMPOSITION OF MANUFACTURING PROCESSES}

The decomposition of manufacturing processes is categorised as high volume, medium volume and low volume, as shown in Figure 1. The decomposition shows that each sub process has its own characteristics and depends on the nature of the company's business. Two extreme processes are continuous line production (fast extreme) and project shop (slow extreme). Other processes lie in between these two extremes of the manufacturing spectrum (Sipper and Bulfin, 1998). Process flow patterns become less complex with cellular, line and continuous flow compared with jobbing and project. If 
the product has a high variety and low volume, it suggests that project or functional production is applied. The characteristics of manufacturing processes are illustrated in Table 1.

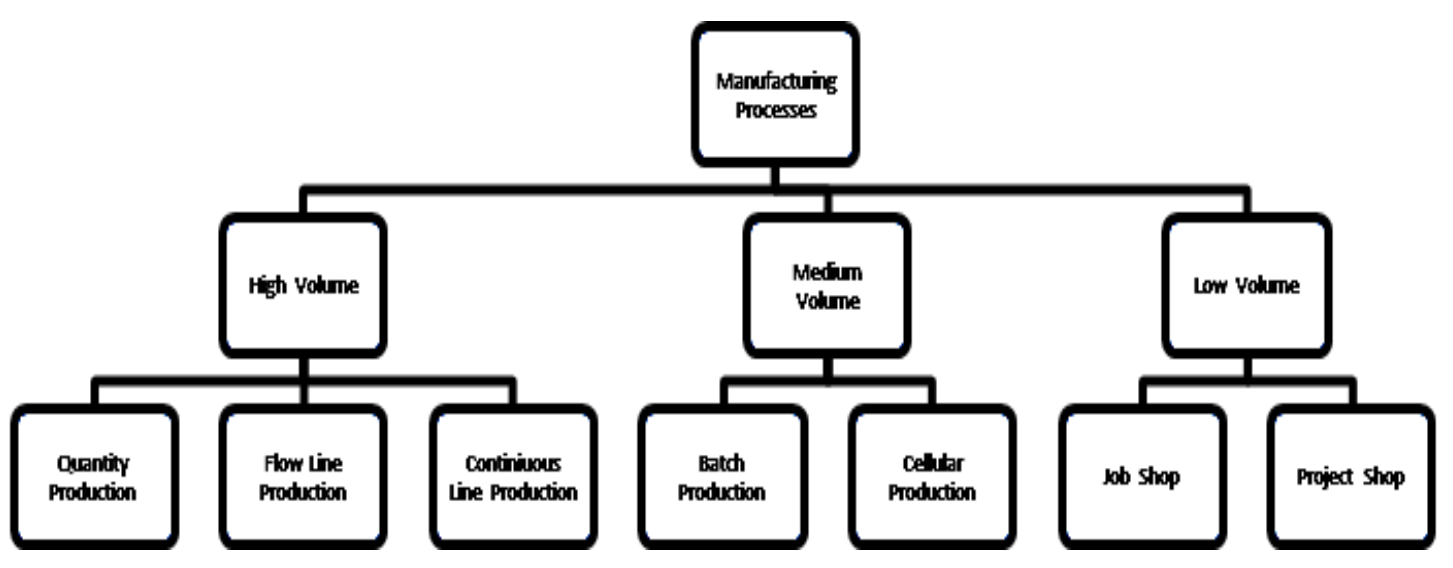

Figure 1. Decomposition of manufacturing processes.

Table 1. Typical characteristics of process choices (adapted from (Hill. 1993))

\begin{tabular}{|c|c|c|c|c|c|c|}
\hline $\begin{array}{l}\text { Manufacturing } \\
\text { aspects }\end{array}$ & Project & Jobbing & Batch & Cellular & Line & Continuous \\
\hline $\begin{array}{l}\text { Nature of the } \\
\text { process } \\
\text { technology }\end{array}$ & $\begin{array}{l}\text { Oriented } \\
\text { towards } \\
\text { general } \\
\text { purpose }\end{array}$ & Universal & Dedicated & Dedicated & Dedicated & $\begin{array}{l}\text { Highly } \\
\text { dedicated }\end{array}$ \\
\hline $\begin{array}{l}\text { Process } \\
\text { flexibility }\end{array}$ & High & High & Low & Low & Low & Inflexible \\
\hline $\begin{array}{l}\text { Production } \\
\text { volumes }\end{array}$ & Low & Low & High & High & High & Very high \\
\hline $\begin{array}{l}\text { Changes in } \\
\text { capacity }\end{array}$ & Incremental & Incremental & $\begin{array}{l}\text { Stepped } \\
\text { change }\end{array}$ & $\begin{array}{l}\text { Stepped } \\
\text { change }\end{array}$ & $\begin{array}{l}\text { Stepped } \\
\text { change }\end{array}$ & New facility \\
\hline $\begin{array}{l}\text { Key } \\
\text { manufacturing } \\
\text { task }\end{array}$ & $\begin{array}{l}\text { To meet } \\
\text { specs/ } \\
\text { delivery } \\
\text { schedules }\end{array}$ & $\begin{array}{l}\text { To meet } \\
\text { specs/ } \\
\text { delivery } \\
\text { schedules }\end{array}$ & $\begin{array}{l}\text { Low cost } \\
\text { production }\end{array}$ & $\begin{array}{l}\text { Low cost } \\
\text { production }\end{array}$ & $\begin{array}{l}\text { Low cost } \\
\text { production }\end{array}$ & $\begin{array}{l}\text { Low cost } \\
\text { production }\end{array}$ \\
\hline
\end{tabular}

These characteristics lead to the choice of process related to volume, as illustrated in Figure 2 (Hill. 1993). The figure clearly shows the relationship between volume and process choice. Starting from project shop, as volume starts to increase the product variety starts to decrease. It also shows that batch production is medium volume production and has bigger scope for mixed-volume, mixed-variety production. Flow line and continuous processing are undoubtedly the choices for high volume and low variety. This figure also shows examples of the types of business related to the choice of process, such as civil engineering, automotive and petrochemical. 


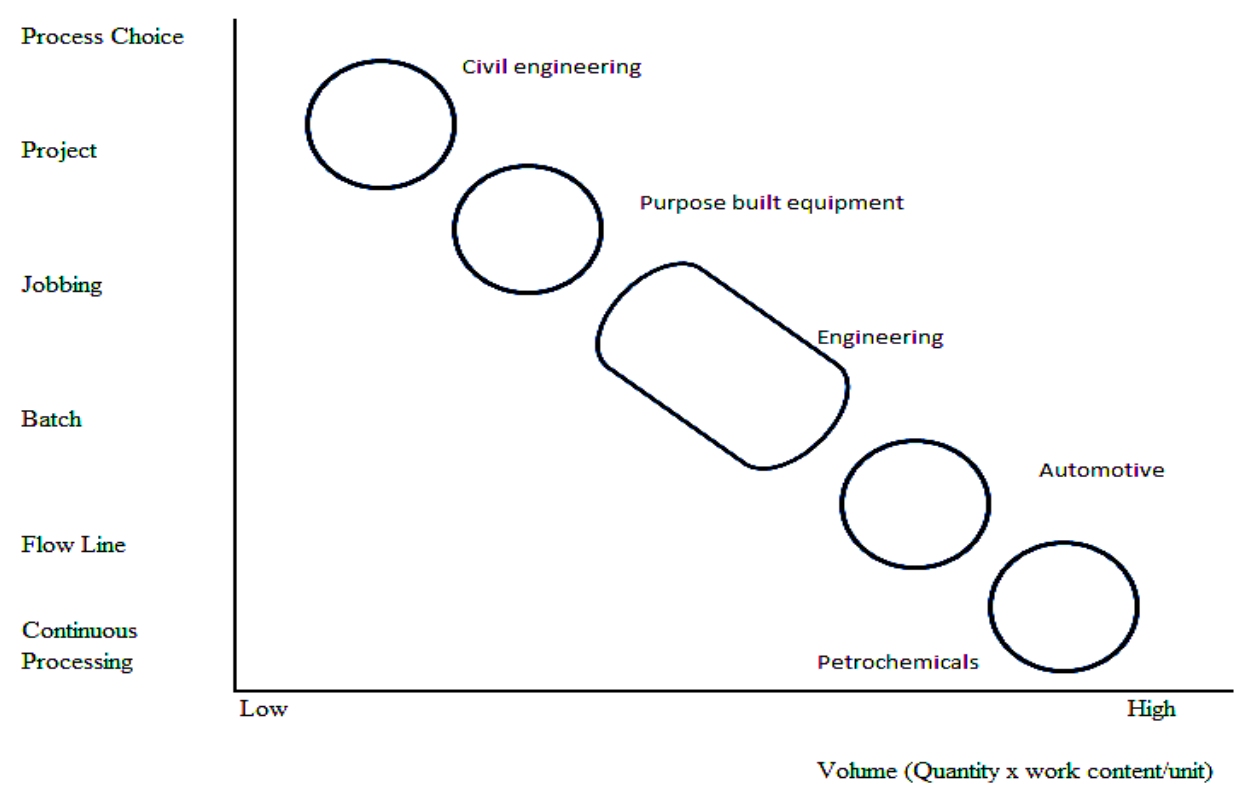

Figure 2. Choice of process related to volume (Hill. 1993).

According to Askin and Standridge (1993), the combination of product demand volume and product variety is dependent upon the appropriate layout, as shown in Figure 3. It suggests that product layout is suitable for high volume, low variety production; cellular layout for mixed-volume, mixed-variety production; and process layout for low volume, high variety production. These layout scenarios give companies a choice for adjusting their working environment to suit the product demand volume. However, the adjustment is not necessarily easy, because the company has to restructure a part, or the whole of the manufacturing environment for the adaption.

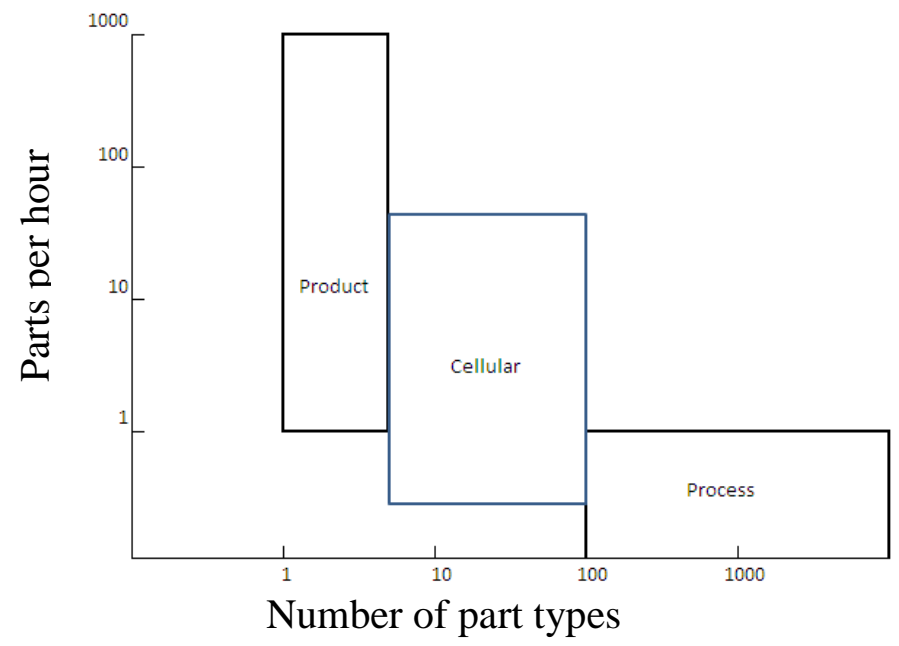

Figure 3. Relationship of product demand and variety (Askin and Standridge, 1993).

According to Ah Kioon et al. (2009), global market competition has forced manufacturers to have integrated manufacturing, in order to adapt to the changing product variety demanded by the customers. Therefore, the best possible zone in which to apply the strategy is in the medium-variety, medium-volume zone, as illustrated in Figure 4. Moreover, Figures 2 and 3 also support the idea of concentrating the medium 
region as the potential zone for global market competition. This is because the medium region offers more flexibility in the manufacturing environment, in order to fulfil different market segments and demands. According to Sipper and Bulfin (1998), the integration should include: Cellular Manufacturing Systems (CMS), Flexible Manufacturing Systems (FMS) and Computer Integrated Manufacturing (CIM). The aim is to achieve economic production by having a wide variety of products. It also suggested that the extreme zones of the high volume-low variety and low volume-high variety are best served by fixed automation and job shop, respectively.

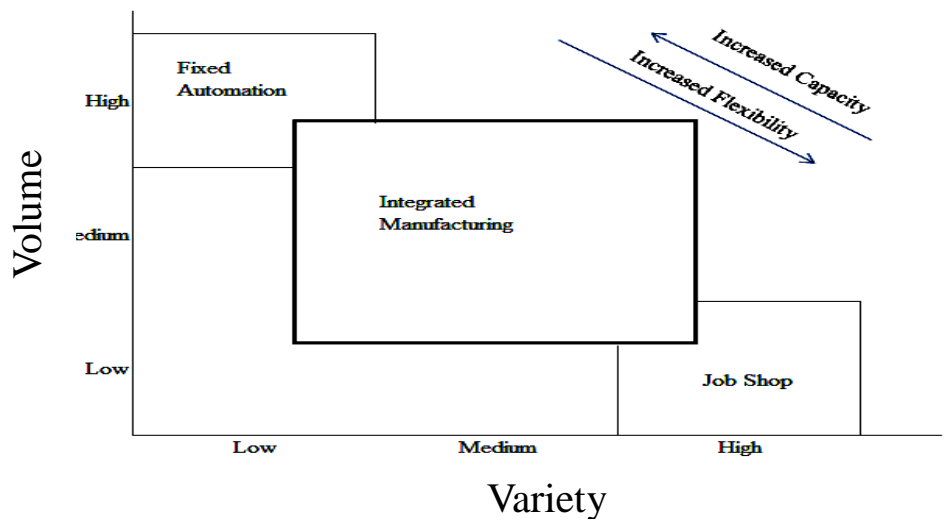

Figure 4. A variety-volume plot (adapted from Sipper and Bulfin (1998)).

\section{High Volume Manufacturing}

High volume manufacturing (also known as mass production) involves producing products in large quantities (Váncza and Egri, 2006). According to Partanen and Haapasalo (2004), the term mass production is used because of the high demand rate for a particular product. Normally, high volume manufacturing means the company produces large quantities of only a small number of different products. This type of manufacturing is associated with long assembly lines where factory workers or machines continuously turn out the same product month after month. According to Özcan and Toklu (2009), the obvious characteristic of a high volume production is that operations are linked together in an assembly line. After completion of one operation on a product, it moves directly to the next operation in the assembly line. The process continues until the final stage in the assembly line where the finished product is completed. There are two categories of high volume production; quantity production and flow line production as shown in Figure 5.

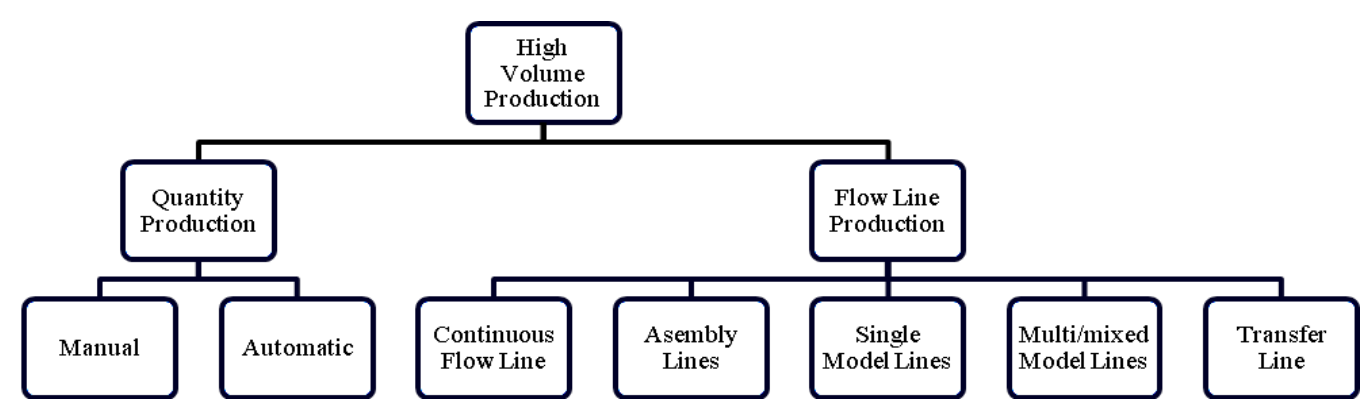

Figure 5. Categories of high volume production. 


\section{Quantity Production}

Quantity production is one category of high volume manufacturing, which concentrates on the mass production of a single product by using single standard equipment (Cárdenas-Barrón, 2009). For example, products that come out from a stamping press, which is a straightforward process, especially for the blank shapes (Kamalapurkar and Date, 2006). The process is a continuous operation with material fed to the machine either manually or automatically. The machine turns the material into the final product and the same process continues until the desired quantity is achieved.

\section{Flow Line Production}

Flow line production focuses on multiple pieces of equipment or workstations that are arranged in the process sequence (Quadt and Kuhn, 2007). According to Drira et al. (2007), flow line production is characterised by high volume, repetitive and short cycle work. The work piece physically moves through this sequence in order to complete the process and finally become the end product. The sequence is also known as product layout because it is arranged in a long line of workstations and usually connected by conveyors. Product layouts, as shown in Figure 6, are designed for a specific product, such as Product $X$ or Product $Y$ (Kara et al., 2009). In flow line production, machines are oriented and set-up to perform operations on the product as it flows in a logical sequence down the line (Chen and Chen, 2009). This is why machines in flow line production are often designed specifically for one product and is not necessarily easily adapted to others (Quadt and Kuhn, 2007). There are also mixed model lines that can be produced out of the base product (Boysen et al., 2009 and Jabbarizadeh et al., 2009). However, the more diverse the products made, the less efficient the assembly line becomes. In addition, there is little work-in-process inventory as the product moves from one operation to another. Hence, line balancing is important so that the different processes in the operation are accomplished in the period and have the same capacity (Sabuncuoglu et al., 2009). There are several types of high volume manufacturing methods implemented in various industries and those methods are described below.

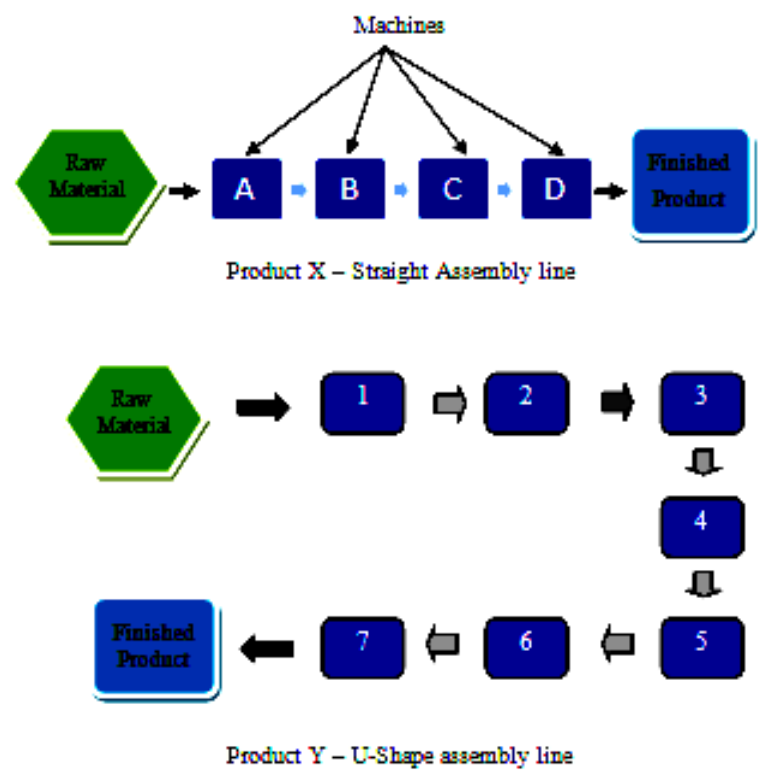

Figure 6. Product Layouts (adapted from Kara et al., (2009)). 


\section{Assembly Lines}

An assembly line is a manufacturing process that has workstations linked by conveyors or a similar material handling system, so that each product goes from one operation directly to the next and so on (Özcan and Toklu, 2009). According to Boysen et al. (2008), an assembly line consists of a number of workstations $\mathrm{k}=1, \ldots, \mathrm{m}$ that consistently perform certain operations on a workpiece in a cycle time (maximum or average time available for each work cycle). In an assembly line operation, the total amount of work is segregated into a set $\mathrm{V}=\{1, \ldots, \mathrm{n}\}$ of named task operations. Therefore, to perform a task $\mathrm{j}$, takes a task time $\mathrm{t}_{\mathrm{j}}$ and requires a certain amount of machines and/or operators. Finally, the total workload necessary for producing the product is measured by the sum of task times $\mathrm{t}_{\text {sum. }}$. As a result, each product follows the same routing of operations with identical final products expected at the end of the line. The complexity in the process of producing a product is mainly dependent upon the number of its components and the assembly levels. The component structure of a product is defined as the Bill of Materials (BOM) (Chan et al., 2009). The assembly line is classified as a single-model production line when every product produced at the end is identical. Fundamentally, assembly lines were developed for a cost-efficient high quantity production of a single standardised product (Boysen et al., 2009).

\section{Single-model Lines}

According to Özcan and Toklu (2009), single-model assembly lines are purposely designed to produce a mass volume of standardised, homogeneous products and are not appropriate for a high variety of products. This type of assembly line is commonly used in a high volume manufacturing environment because it enables assembly of workpieces by operators with limited training (Cevikcan et al,. 2009). With the advance of manufacturing technologies and systems, automated set-up operations at negligible set-up times and cost, can be considered for upgrading the existing single-model assembly line (Boysen et al., 2008). This single-model assembly line can produce more than one product, as long as neither set-ups nor significant variations in operating times occur.

\section{Multi/mixed Model Lines}

According to Gamberi et al. (2008), there is an increasing global trend that companies offer a wide selection of products to their customers. For example, product options for cars, such as a manual or electric sunroof and air conditioning systems are available for customers to select. The manufacturers of these products need to manage the product variety by introducing a multi/mixed-model assembly line system that produces similar items or options of the same product requiring analogous tasks (Boysen et al., 2009). They are being used in a range of industries and it improves the flexibility to cope with the changes in global demand (Özcan and Toklu, 2009). Multi-model assembly lines, as illustrated in Figure 7, produce one set of products before continuing with another set of products on the same assembly line. According to Boysen et al. (2008), in multi-model production, the homogeneity of the BOM and the production processes are not sufficient to allow for continuous production sequences. Therefore, the assembly process for these kinds of products needs to be in batches, in order to avoid set-up times and high costs. 


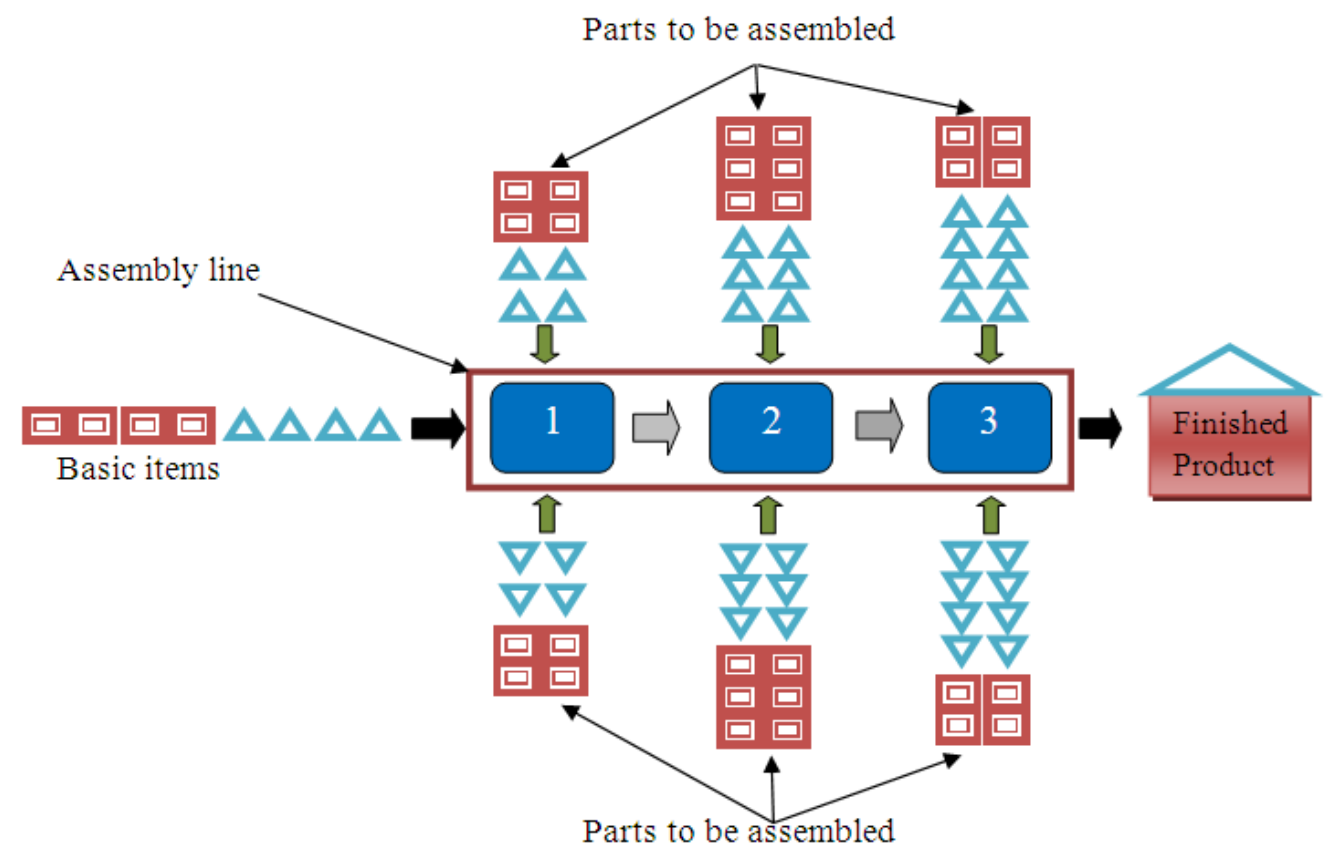

Figure 7. Multi-model assembly (adapted from Boysen et al. (2008)).

On the other hand, mixed-model assembly lines, as illustrated in Figure 8, produce products in a mixed sequence. According to Cevikcan et al., (2009), this kind of system has superior benefits compared with the traditional assembly line in terms of system flexibility, lead time, cost and product quality. Boysen et al., (2008) stated that the versatility of the system with the application of flexible workers and machinery, means that the set-up times between models could be reduced sufficiently enough to be ignored. Hence, an intermixed model of common base product sequences can be produced on the same assembly line. It is assumed that the products are different in specific customised product attributes or options (Boysen et al., 2009).

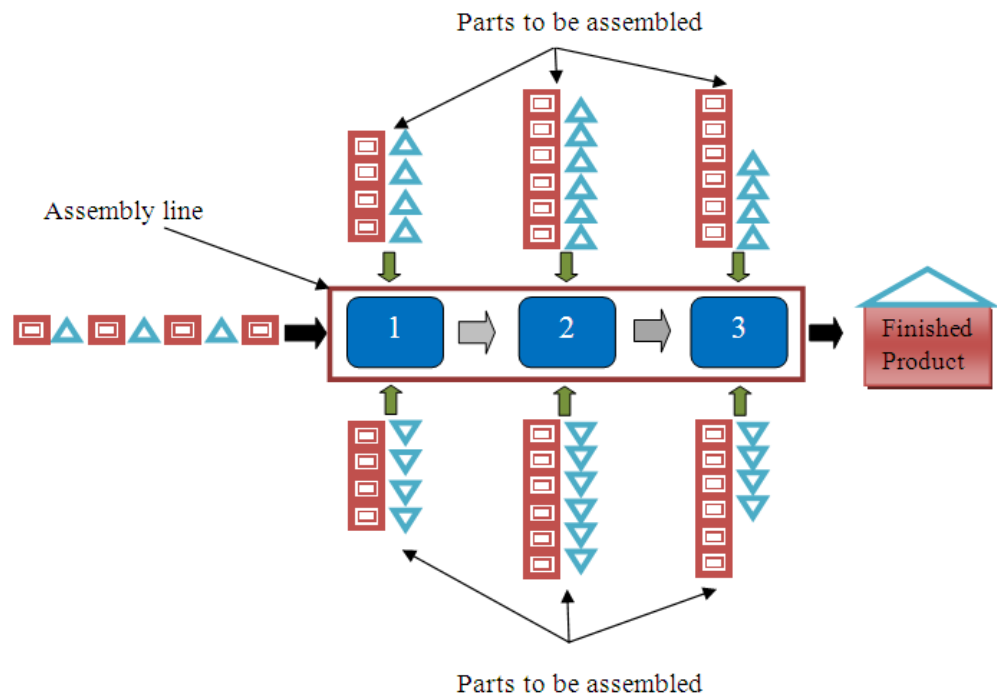

Figure 8. Mixed model lines (adapted from Boysen et al., (2008)). 


\section{Transfer Lines}

Transfer lines or fully automated lines are implemented in the manufacturing environment, mainly to perform jobs more economically, precisely and safely (Boysen et al., 2008). The advantage of transfer lines is the variation of products, produced by using the same production line. It creates the opportunity to cater to the demand for product varieties. Normally, machines capable of changing tools automatically, to perform multiple jobs at varying speeds, service these lines. According to Dolgui and Ihnatsenka (2009), transfer lines work by passing workpieces sequentially through all workstations at a constant and controlled speed. These types of lines are designed for mass production of a single product or a family of similar products. The high degree of automation of the lines means that the programmed production period can be for an extended length of time. Furthermore, the synchronisation of the product's movements in the line avoids buffers in between the workstations. Among the applications of transfer lines are the weld shop, paint shop and body shop of the automotive industry (Boysen et al., 2008).

\section{Continuous Line Production}

According to Sipper and Bulfin (1998), continuous line production is a radical extension of flow line production. The process works by passing basic materials through different stages during which they are refined or processed into one or more products, such as chemicals (Tousain and Bosgra, 2006), food (Brierley et al., 2006) and steel mills (Tang and Wang, 2008). According to Weinekötter (2009), the continuous line process is based on high volume demand and the materials involved move easily and constantly from one stage of the process to another. Discrete units are not produced but liquids or gases, flowing through pipes are transformed into the final products. With a continuous flow process, one can estimate realistically how long it takes to transform raw materials into a specific product (Floudas and Lin, 2004). Production of this type involves very high investment costs, which must be justified by high volume demand. According to Brierley et al. (2006), capital investment and automation for this type of production are often the most expensive compared with other processes. This is because the processes are designed to run daily and continuously because of the high costs incurred in starting up and closing down (Hill, 1993). In continuous processing, as materials flow from one stage to another, it is important to monitor and adjust the flow to ensure the quality of the product (Shaik et al., 2009). Normally, this is done automatically and the use of labour in these situations is mainly to check the system functions correctly. On normal sales levels, this type of process can be very productive and profitable (Tousain and Bosgra, 2006).

\section{Medium Volume Manufacturing}

Medium volume manufacturing is between high volume and low volume manufacturing. The volumes subjectively depend on the product types that a company produces. Medium volume manufacturing has two types of facilities that depend on product variety (Das et al., 2007). The first type is batch production and the second type is cellular manufacturing. Batch production is used when product variety is substantially different, whereas cellular manufacturing is used when variety between products is very small (Groover, 2007). 


\section{Batch Production}

Batch production is used when there are varieties of different products being manufactured but in smaller quantities (Kalpakjian and Schmid, 2006). It is normal to have the same machine handle operations on a number of different products. Once one batch of products is finished, the manufacturing system is changed over to produce another batch of different products (Floudas and Lin, 2004). However, by sharing the machines, lost production time is higher due to the set-up time during the changeover process. According to Gamberi et al. (2008), the process will need to be reset each time the new batch is scheduled to start. Among the constraints on the process are cleaning, cooling and maintenance. According to Drira et al. (2007), the batch production layout groups equipment by function rather than by product, which is suitable for a wide variety of product factories The product is moving from department to department throughout the process within the factory. The batch flow depends on the job order, such as routings, process steps and time spent on certain departments. The typical batch flow process is the set menu of products to be produced, frequency and set quantity or lot size (Schmenner, 1993). Due to the competitive market, normally batches are produced in an established lot size that moves into stock for future customer orders (Das et al., 2007). Examples of batch production are the chemical industry, metal forming and steel pipe manufacturing (Gamberi et al., 2008).

\section{Cellular Manufacturing}

Another type of medium volume manufacturing is Cellular Manufacturing (CM), also known as Group Technology. According to Li (2003), the main purpose of CM is to group machines into machine cells and parts into part families. CM also arranges operators according to the machines in order to design a high performance factory. Angra et al. (2008), stated that the philosophy of CM is to capitalise on similar, recurrent activities with broad applicability, potentially affecting entire areas of the manufacturing organisation. The concept of $\mathrm{CM}$ is to segregate a manufacturing system into sub-systems in order to improve the overall efficiency of the system (Drira et al., 2007). CM has become a new method for manufacturing systems, which are traditionally based on functional tasks (Agarwal, 2008). The increasing applicability of this method is due to the shorter product life cycle, increasing demand for customisation and customer expectations for cost and quality. The emphasis of CM is on group effort and individuals that may move the workpiece from machine to machine through the cell without waiting between operations (Panchalavarapu and Chankong, 2005).

\section{Flexible Manufacturing System}

According to Kumar and Sridharan (2009), a Flexible Manufacturing System (FMS) is a system that integrates Computer Numerically Controlled (CNC) machines and automated Material Handling Systems (MHS) that work together under computer control. Flexibility deals with high quality customised products and focuses on fast delivery of products to market with reasonable price. Basic flexibilities in manufacturing include machine flexibility, material handling flexibility and operational flexibility. The aim of the system is to achieve both production flexibility and high productivity in order to meet the current global demands. The key characteristics of the system are the ability to efficiently produce a diverse range of parts and the capability to 
respond quickly to part-mix changes Sujono and Lashkari (2007). According to Sujono and Lashkari (2007), the most critical issue in dealing with FMS is managing the flow of parts and tools. This is because the flexible of the machines in FMS can perform a variety of tasks when provided with the required tools. The high variety of parts requires a high number of cutting tool types. Hence, it requires systematic planning and monitoring in order to control the tool mix as well as the cost, for the efficient operation of FMS.

\section{Low Volume Manufacturing}

Low volume manufacturing normally makes a low quantity of specialised, complex and customised products (Bellgran and Aresu, 2003). This type of manufacturing requires a highly skilled labour force and maximum flexibility, in order to cater for product variations. Examples of this type of manufacturing are the aircraft, ship and automotive industries. According to Williamson (2006), low volume manufacturing is always found with a high flexibility manufacturing program. To achieve this concept, the manufacturer must consistently review the available technology for both product design and facility design. This is to minimise the use of a product's specific tooling and to maximise asset utilisation and reuse of equipment. Miltenburg (2008) suggested that a low volume manufacturing company should consider lean production and innovativeness, in addition to flexible manufacturing, as the most important manufacturing outputs. Engle (2008), suggested that a design team should consider a component sharing concept in producing a high variety of products, so as to maximise the use of commonly available components within the company. According to Wrobel and Laudanski (2008), low volume manufacturing performs production based on "make to order". Niche vehicle manufacturing is an example of low volume automotive production that requires high customisation (Meichsner, 2009). A modularisation concept is one of the customisation methods that pre-combines a large number of components into modules (Pandremenos et al., 2009). It works by assembling these modules off-line and then combining these modules at the main assembly line to form a complete assembled model. Due to the pre-assembled modules, the process at the main assembly line should be small and simple tasks.

According to Zhang et al. (2009), manufacturers for low volume manufacturing should consider the approach of product development flexibility and product concept flexibility. Product development flexibility is the ability to design and introduce a variety of new products quickly with minimal distractions. Product concept flexibility is the ability to anticipate the market demand and customer needs. Koste and Malhotra (2000) suggested that worker's job rotation flexibility is also important, because workers who are trained to perform job rotation will be multi-tasking experts and become an asset in a low volume manufacturing environment. There are two types of low volume manufacturing methods, jobbing or job shop and project shop.

\section{Project Shop}

Project shop deals with a particular product that is single, unique, and customised. Project shop is used for large projects, such as civil engineering contracts, ships, buildings and aeroplanes, because the size of the product makes it impossible to move between processing operations. According to Drira et al. (2007), project shop uses a 
fixed position layout to manufacture large size products, such as ships or aircraft, the product is fixed at one place while the resources, materials and equipment are supplied to it. The project shop normally makes full use of certain skills and capabilities when needed, depending on the requirements and little or no use of those skills at other times. Project job also involves external resources, such as skilled people and equipment (Bellgran and Aresu, 2003). Therefore, coordination of full time, part time or subcontracted skills and capabilities are very important to keep the project on schedule. Resources can be many and varied; therefore, the total coordination of those skills and capabilities requires a lot of attention for planning and scheduling. The quality of any project depends greatly on the skills, teamwork and care of the members of the project team.

\section{Jobbing}

Jobbing is used to fulfil a special and particular product ordered by customers, such as fabricating and metalworking (Dixon, 2008). Hence, it is the most flexible process in manufacturing a wide variety of products. Job shop typically uses a process layout in arranging the equipment (Bertrand and Sridharan, 2001), also known as a functional layout, because the equipment is arranged according to functions. For example, turning machines may form one department, milling a second and grinding processes a third. Normally a job shop has a diverse array of facilities and capabilities from which to choose possibly with differing efficiencies (Gao et al., 2007). According to Kher (2000), the responsibility for making the product is normally given to highly skilled operators. The operators themselves decide the best way to make it, choose the equipment and then complete all or most of the operations involved, including checking the quality at each stage. Batches of products assigned to a work centre may require very different tooling and setup. Furthermore, the material flow in a job shop can follow a complex movement pattern (Fan et al., 2007). The materials can move in many directions and can loop back to the same equipment later in the operation.

According to Chan et al. (2009), for a job shop environment, there are $\mathrm{m}$ machines and $n$ jobs in the operation. Each machine can only operate one job order at one time. This means that each job can only use a particular machine once and in a strict sequence, so that all the processes are completed according to the schedule. However, due to the high demand from customers, a flexible job shop is considered necessary to cope with tight schedules. According to Fattahi et al. (2009), flexible job shop scheduling introduces an approach known as overlapping in operations. In this approach, each operation may overlap with others because of its similarity in process and limitations of structural constraints, such as the dimension of the parts. As soon as the first piece is processed on a machine, it goes directly to the next machine without waiting for all the operations to be completed on that particular machine.

\section{CONCLUSIONS}

This paper has provided a review of the manufacturing environment. It details manufacturing processes and their decompositions, including the spectrum of manufacturing processes involved with types of production that determine the volumes and varieties of products. This paper reviews three types of manufacturing processes that involve high, medium and low production volumes. These manufacturing segments 
have different methods of production depending on the types of business, products, facility and layout.

\section{ACKNOWLEDGEMENTS}

The financial support by the Malaysian Government, Universiti Malaysia Pahang and Bradford University for this research is gratefully acknowledged.

\section{REFERENCES}

Agarwal, A. 2008. Partitioning bottleneck work center for cellular manufacturing: An integrated performance and cost model. International Journal of Production Economics, 111(2): 635-647.

Ah kioon, S., Bulgak, A.A. and Bektas, T. 2009, Integrated cellular manufacturing systems design with production planning and dynamic system reconfiguration. European Journal of Operational Research, 192(2): 414-428.

Amoako-Gyampah, K. and Acquaah, M. 2008. Manufacturing strategy, competitive strategy and firm performance: An empirical study in a developing economy environment. International Journal of Production Economics, 111(2): 575-592.

Angra, S., Sehgal, R. and Samsudeen Noori, Z. 2008. Cellular manufacturing-A timebased analysis to the layout problem. International Journal of Production Economics, 112(1): 427-438.

Askin, R.G. and Standridge, C.R. 1993. Modeling and analysis of manufacturing systems. New York: John Wiley \& Sons, Inc.

Balakrishnan, J., Eliasson, J.B. and Sweet, T.R.C. 2007. Factors affecting the evolution of manufacturing in Canada: An historical perspective. Journal of Operations Management, 25(2): 260-283.

Bellgran, M. and Aresu, E. 2003. Handling disturbances in small volume production. Robotics and Computer-Integrated Manufacturing, 19(1-2): 123-134.

Bertrand, J.W.M. and Sridharan, V. 2001. A study of simple rules for subcontracting in make-to-order manufacturing. European Journal of Operational Research, 128(3): 509-531.

Boysen, N., Fliedner, M. and Scholl, A. 2009. Sequencing mixed-model assembly lines: Survey, classification and model critique. European Journal of Operational Research, 192(2): 349-373.

Boysen, N., Fliedner, M. and Scholl, A. 2008. Assembly line balancing: Which model to use when? International Journal of Production Economics, 111(2): 509-528.

Brierley, J.A., Cowton, C.J. and Drury, C. 2006. A comparison of product costing practices in discrete-part and assembly manufacturing and continuous production process manufacturing. International Journal of Production Economics, 100(2): 314-321.

Cárdenas-Barrón, L.E. 2009. Economic production quantity with rework process at a single-stage manufacturing system with planned backorders. Computers \& Industrial Engineering, 57(3): 1105-1113.

Castaldi, C. 2009. The relative weight of manufacturing and services in Europe: An innovation perspective. Technological Forecasting and Social Change, 76(6): 709-722.

Cevikcan, E., Durmusoglu, M.B. and Unal, M.E. 2009. A team-oriented design methodology for mixed model assembly systems. Computers \& Industrial 
Engineering, 56(2): 576-599.

Chan, F.T.S., Wong, T.C. and Chan, L.Y. 2009. An evolutionary algorithm for assembly job shop with part sharing. Computers \& Industrial Engineering, 57(3): 641-651.

Chen, C.L. and Chen, C.L. 2009. A bottleneck-based heuristic for minimizing makespan in a flexible flow line with unrelated parallel machines. Computers \& Operations Research, 36(11): 3073-3081.

Das, K., Lashkari, R.S. and Sengupta, S. 2007. Reliability consideration in the design and analysis of cellular manufacturing systems. International Journal of Production Economics, 105(1): 243-262.

Dixon, D. 2008. Low volume, high variety production: no problem for lean in the job shop. Fabricating and metalworking, October: 20-23.

Dolgui, A. and Ihnatsenka, I. 2009. Balancing modular transfer lines with serial-parallel activation of spindle heads at stations. Discrete Applied Mathematics, 157(1): 68-89.

Drira, A., Pierreval, H. and Hajri-Gabouj, S. 2007, Facility layout problems: A survey. Annual Reviews in Control, 31(2): 255-267.

Engle, P. 2008. Low-volume lean. Industrial Engineering, 40(12): 18.

Fan, K., Zhang, R. and Xia, G. 2007. Solving a Class of Job-Shop Scheduling Problem based on Improved BPSO Algorithm. Systems Engineering - Theory \& Practice, 27(11): 111-117.

Fattahi, P., Jolai, F. and Arkat, J. 2009. Flexible job shop scheduling with overlapping in operations. Applied Mathematical Modelling, 33(7): 3076-3087.

Floudas, C.A. and Lin, X. 2004. Continuous-time versus discrete-time approaches for scheduling of chemical processes: a review. Computers \& Chemical Engineering, 28(11): 2109-2129.

Gamberi, M., Gamberini, R., Manzini, R. and Regattieri, A. 2008. An analytical model to evaluating the implementation of a batch-production-oriented line. International Journal of Production Economics, 111(2): 729-740.

Gao, J., Gen, M., Sun, Linyan. and Zhao, X. 2007. A hybrid of genetic algorithm and bottleneck shifting for multiobjective flexible job shop scheduling problems. Computers \& Industrial Engineering, 53(1): 149-162.

Groover, M.P. 2007. Fundamentals of modern manufacturing: materials, process, and system. Third edition ed, New Jersey: John Wiley and Sons, Inc.

Hill, T. 1993. Manufacturing strategy: the strategic management of the manufacturing function. 2nd ed, London: The Macmillan Press Ltd.

Jabbarizadeh, F., Zandieh, M. and Talebi, D. 2009. Hybrid flexible flowshops with sequence-dependent setup times and machine availability constraints. Computers \& Industrial Engineering, 57(3): 949-957.

Kalpakjian, S. and Schmid, S.R. 2006. Manufacturing engineering and technology. Fifth ed, Singapore: Prentice Hall.

Kamalapurkar, R.L. and Date, P.P. 2006. Minimizing wastage of sheet metal for economical manufacturing. Journal of Materials Processing Technology, 177(13): 81-83.

Kara, Y., Paksoy, T. and Chang, C.T. 2009. Binary fuzzy goal programming approach to single model straight and U-shaped assembly line balancing. European Journal of Operational Research, 195(2): 335-347.

Karim, M.A., Smith, A.J.R, Halgamuge, S.K. and Islam, M.M. 2008. A comparative study of manufacturing practices and performance variables. International Journal of Production Economics, 112(2): 841-859. 
Kher, H.V. 2000. Examination of worker assignment and dispatching rules for managing vital customer priorities in dual resource constrained job shop environments. Computers \& Operations Research, 27(6): 525-537.

Kost, G.G. and Zdanowicz, R. 2005. Modeling of manufacturing systems and robot motions. Journal of Materials Processing Technology, 164-165: 1369-1378.

Koste, L.L. and Malhotra, M.K. 2000. Trade-offs among the elements of flexibility: a comparison from the automotive industry. Omega, 28(6): 693-710.

Kumar, S.N. and Sridharan, R. 2009. Simulation modelling and analysis of part and tool flow control decisions in a flexible manufacturing system. Robotics and Computer-Integrated Manufacturing, 25(4-5): 829-838.

Li, M.L. 2003. The algorithm for integrating all incidence matrices in multi-dimensional group technology. International Journal of Production Economics, 86(2): 121131.

Meichsner, T.P. 2009. Migration Manufacturing - A New Concept for Automotive Body Production, in Changeable and Reconfigurable Manufacturing Systems, Springer London: London.

Miltenburg, J. 2008. Setting manufacturing strategy for a factory-within-a-factory. International Journal of Production Economics, 113(1): 307-323.

Özcan, U. and Toklu, B. 2009, Balancing of mixed-model two-sided assembly lines. Computers \& Industrial Engineering, 57(1): 217-227.

Panchalavarapu, P.R. and Chankong, V. 2005. Design of cellular manufacturing systems with assembly considerations. Computers \& Industrial Engineering, 48(3): 449-469.

Pandremenos, J., Paralikas, J., Salonitis, K. and Chryssolouris, G. 2009. Modularity concepts for the automotive industry: A critical review. CIRP Journal of Manufacturing Science and Technology, 1(3): 148-152.

Partanen, J. and Haapasalo, H. 2004. Fast production for order fulfillment: Implementing mass customization in electronics industry. International Journal of Production Economics, 90(2): 213-222.

Quadt, D. and Kuhn, H. 2007. A taxonomy of flexible flow line scheduling procedures. European Journal of Operational Research, 178(3): 686-698.

Sabuncuoglu, I., Erel, E.and Alp, A. 2009. Ant colony optimization for the single model U-type assembly line balancing problem. International Journal of Production Economics, 120(2): 287-300.

Schmenner, R.W. 1993. Production/operations management:from the inside out, New Jersey: Prentice Hall.

Shaik, M.A., Christodoulos, A.F., Josef, K. and Hans-Joachim, P. 2009. Production scheduling of a large-scale industrial continuous plant: Short-term and mediumterm scheduling. Computers \& Chemical Engineering, 33(3): 670-686.

Sipper, D. and Bulfin, R.L. 1998. Production:planning, control, and integration, Singapore: McGraw-Hill Companies, Inc.

Stewart, D. Is Japan giving up?. 2010 [cited 201016 March 2010]; Available from: http://www.huffingtonpost.com/devin-stewart/is-japan-givingup_b_490249.html.

Sujono, S. and Lashkari, R.S. 2007. A multi-objective model of operation allocation and material handling system selection in FMS design. International Journal of Production Economics, 105(1): 116-133. 
Swink, M., Narasimhan, R. and Wang, C. 2007. Managing beyond the factory walls: Effects of four types of strategic integration on manufacturing plant performance. Journal of Operations Management, 25(1): 148-164.

Tang, L. and Wang G. 2008. Decision support system for the batching problems of steelmaking and continuous-casting production. Omega, 36(6): 976-991.

Tousain, R.L. and Bosgra O.H. 2006. Market-oriented scheduling and economic optimization of continuous multi-grade chemical processes. Journal of Process Control, 16(3): 291-302.

Váncza, J. and Egri P. 2006. Coordinating supply networks in customized mass production: - a contract-based approach. CIRP Annals - Manufacturing Technology, 55(1): 489-492.

Wang, Z., Du, P. and Yu Y. 2009. An intelligent modeling and analysis method of manufacturing process using the first-order predicate logic. Computers \& Industrial Engineering, 56(4): 1559-1565.

Weinekötter, R. 2009. Compact and efficient continuous mixing processes for production of food and pharmaceutical powders. Trends in Food Science \& Technology, 20(S1): 48-50.

Williamson, I. 2006. Low Volume; high flexibility (automotive industry). IEEE Manufacturing Engineer, 84(6): 40- 43.

Wrobel, J. and Laudanski M. 2008. Cost assessment in design of low volume manufacture machines. Automation in Construction, 17(3): 265-270.

Zhang, Q., Vonderembse, M.A. and Cao, M. 2009. Product concept and prototype flexibility in manufacturing: Implications for customer satisfaction. European Journal of Operational Research, 194(1): 143-154. 